\title{
In situ end labelling: effect of proteolytic enzyme pretreatment and hydrochloric acid
}

N J Carr, I C Talbot

\begin{abstract}
Aim-To determine the effect of dilute hydrochloric acid on the in situ end labelling (ISEL) reaction, with and without a variety of different proteolytic enzymes. Methods-Sections of tissue fixed in buffered formalin were pretreated with trypsin, protease XIV (at two different concentrations), or protease XXIV (for two different incubation times), with and without subsequent $1 \mathrm{M}$ hydrochloric acid treatment. The results were compared with those obtained using hydrochloric acid alone, with proteinase $K$, and pepsin pretreatment, and with no pretreatment.

Results-When hydrochloric acid was added to the sections in addition to trypsin, protease XIV, and protease XXIV, there was a significant increase in ISEL reactivity in both apoptotic nuclei and morphologically normal nuclei. Hydrochloric acid alone had no significant effect.

Conclusion-Hydrochloric acid has a distinctive effect on the ISEL reaction that is dependent on prior proteolytic digestion. (F Clin Pathol: Mol Pathol 1997;50:160-163)
\end{abstract}

Keywords: apoptosis; in situ end labelling; DNA polymerase I

DNA strand breaks are a characteristic feature of apoptosis. ${ }^{12}$ In situ end labelling (ISEL) is a technique for demonstrating apoptotic cells in tissue sections using DNA polymerase to incorporate labelled nucleotide into broken DNA strands. ISEL has been used in recent studies as a measure of apoptosis in experimental and clinical material. ${ }^{2-9} \mathrm{~A}$ closely related technique using terminal deoxynucleotidyl transferase (TdT) rather than DNA polymerase is known as TdT mediated dUTP biotin nick end labelling (TUNEL). ${ }^{10-12}$ One advantage of these techniques over conventional morphology is that they may allow demonstration of very early apoptotic changes that may not be visible in haematoxylin and eosin stained sections. Published protocols for both ISEL and TUNEL, including the commercial kits now available, generally include a pretreatment step to allow the reagents access to the DNA when formalin fixed tissue is used. The rationale is that the cross linking effects of formalin would otherwise prevent the reagents from reaching the target DNA. This pretreatment usually involves proteolytic enzyme digestion of the sections; some protocols also call for microwaving in citrate buffer. The pro- teolytic enzymes are usually either pepsin in dilute hydrochloric acid or proteinase $\mathrm{K}^{2-58-13}$ Exceptions to these studies include those by $\vec{T}$ Mundle et al who used pronase with plastic $\triangle$ embedded sections, ${ }^{56}$ and Gold et al who pre- के treated the slides with chloroform but did not $\overrightarrow{0}$ use proteolysis in one study.

Like ISEL, the in situ polymerase chain $\tilde{\omega}^{\circ}$ reaction (PCR) requires pretreatment of sections of formalin fixed, paraffin wax embedded material to allow the reagents access to the target DNA. Some protocols for in situ PCR include incubation with dilute hydrochloric $\vec{\circ}$ acid to help make the tissue more 음 permeable. ${ }^{14}{ }^{15}$ It is not clear what effect the acid has; possibilities include mild acid hy- $\overleftarrow{\subseteq}$ drolysis of nucleic acids, depurination, or an $\frac{\bar{D}}{\overline{1}}$ effect on the nuclear histone proteins. ${ }^{14-16}$

By analogy with in situ PCR, mineral acids could have an important effect in ISEL as both : techniques use DNA polymerase to insert nucleotides into DNA within nuclei or nuclear fragments. This study was designed to test the hypothesis that hydrochloric acid has an effect $\stackrel{\circ}{\mathbb{D}}$ on the ISEL reaction independent of other reagents used in pretreatment, and to compare $\vec{\partial}$ the results with the standard pretreatments of pepsin and proteinase $\mathrm{K}$.

\section{Methods}

We used tissue from three specimens: a moderately differentiated adenocarcinoma of the colon; a high grade malignant lymphoma in a of cervical lymph node; and a normal appendix.

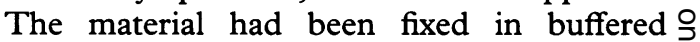
formalin. Sections were cut at $5 \mu \mathrm{m}$ thickness $D$ and placed on positively charged glass slides.

The experimental procedure was based on $N$ the methods of Ansari et al and Wijsman et al. ${ }^{2-4}$ The sections were dewaxed in xylene and $\mathcal{N}$ hydrated in ethanol and water. Endogenous $\omega$ peroxidase activity was quenched by placing the slides in a $1 \%$ solution of hydrogen peroxide for 10 minutes, after which the slides were $\stackrel{\Phi}{\rightarrow}$ washed twice in distilled water.

PRETREATMENT OF SECTIONS

Two slides from each of the three blocks (total $\frac{\Omega}{\overparen{D}}$ six slides) each had pretreatment in separate $\frac{\Omega}{O}$ runs:

1. No pre-treatment

2. $0.1 \mathrm{M}$ hydrochloric acid, 10 minutes

3. $1 \mathrm{M}$ hydrochloric acid, 10 minutes

4. Trypsin $0.1 \%, 15$ minutes

5. Trypsin $0.1 \%, 15$ minutes, followed by $1 \mathrm{M}$ hydrochloric acid, 10 minutes

6. Protease XIV 0.05\%, 15 minutes

7. Protease XIV 0.05\%, 15 minutes, followed by $1 \mathrm{M}$ hydrochloric acid, 10 minutes 
8. Protease XIV 0.5\%, 15 minutes

9. Protease XIV $0.5 \%, 15$ minutes, followed by $1 \mathrm{M}$ hydrochloric acid, 10 minutes

10. Protease XXIV, five minutes

11. Protease XXIV, five minutes, followed by $1 \mathrm{M}$ hydrochloric acid, 10 minutes

12. Protease XXIV, 15 minutes

13. Protease XXIV, 15 minutes, followed by $1 \mathrm{M}$ hydrochloric acid, 10 minutes

14. Proteinase $\mathrm{K}, 0.02 \%, 10$ minutes

15. Pepsin $0.01 \%, 10$ minutes.

The hydrochloric acid was dissolved in distilled water. The trypsin (ICN Biomedicals, Aurora, Ohio, USA) was dissolved in $0.1 \%$ calcium chloride solution, adjusted to $\mathrm{pH} 7.8$ at $37^{\circ} \mathrm{C}$. The protease XIV from Streptomyces griseus (Sigma, Poole, Dorset, UK) was dissolved in $50 \mathrm{mM}$ Tris $\mathrm{HCl}, \mathrm{pH}$ 7.6. The bacterial protease XXIV (Biogenex, San Ramon, California, USA) was obtained in kit form and made up according to the manufacturer's protocol. The proteinase K (Sigma) was dissolved in $50 \mathrm{mM}$ Tris $\mathrm{HCl}$ with $1 \mathrm{mM}$ EDTA, adjusted to $\mathrm{pH}$ 8.5. The pepsin was dissolved in $0.1 \mathrm{M}$ hydrochloric acid. Digestion in trypsin was performed at $37^{\circ} \mathrm{C}$. All other pretreatment reactions were performed at the ambient temperature of the laboratory, which ranged from $22^{\circ} \mathrm{C}$ to $26^{\circ} \mathrm{C}$.

In an additional experiment, slides were incubated for 60 minutes with trypsin or protease XXIV as the pretreatment step.

\section{ISEL REACTIONS}

After pretreatment, the slides were washed three times in distilled water and allowed to dry on the laboratory bench until there was no visible fluid on the sections (about 20 minutes). The buffer solution for the nucleotidepolymerase reaction contained $50 \mathrm{mM}$ Tris $\mathrm{HCl}$, pH 7.4 (Sigma), $5 \mathrm{mM}$ magnesium chloride, $10 \mathrm{mM} 2$-mercaptoethanol, and $0.005 \%$ bovine serum albumin in distilled water. The concentrations of reagents in this buffer were $0.02 \mathrm{mM}$ dATP, dGTP, and dCTP (Sigma), $0.004 \mathrm{mM}$ bio-21-dUTP (Clontech, Palo Alto, California, USA) and $30 \mathrm{units} / \mathrm{ml}$ of DNA polymerase I (Sigma). Enough solution was added to cover the sections completely, and the slides were incubated for 90 minutes in a humid atmosphere at $37^{\circ} \mathrm{C}$, after which they were washed in two changes of phosphate buffered saline (PBS), $\mathrm{pH}$ 7.0.

The incorporation of labelled nucleotide was detected by incubating the slides in a streptavidin-biotin complex solution (Dako, Glostrup, Denmark) for 30 minutes, washing twice in PBS, and then a 3-3' diaminobenzidine-hydrogen peroxide solution (Biogenex). The slides were washed in water, counterstained with haematoxylin, dehydrated, and mounted.

Each run contained a positive and negative control. The positive control was a colonic adenocarcinoma pretreated with $0.1 \%$ pepsin (Sigma) in $0.1 \%$ hydrochloric acid (this procedure results in strong ISEL reactions in normal nuclei as well as apoptotic bodies). The negative control was the same adenocarci-
Table 1 Total scores for each pretreatment (maximum score 18)

\begin{tabular}{lcc}
\hline & Apoptotic cells & Normal cells \\
\hline No pretreatment & 4 & 0 \\
HCl 0.1 M & 5 & 0 \\
HCl 1 M & 4 & 0 \\
Trypsin 0.1\% & 2 & 0 \\
Trypsin 0.1\% + HCl 1 M & 11 & 7 \\
Protease XIV 0.05\% & 9 & 4 \\
Protease XIV 0.05\% + HCl & 16 & 9 \\
Protease XIV 0.5\% + & 0 & 0 \\
Protease XIV 0.5\% + HCl & 18 & 17 \\
Protease XXIV 5 min & 4 & 2 \\
Protease XXIV 5 min + & 15 & 9 \\
HCl & & \\
Protease XXIV 15 min & 2 & 1 \\
Protease XXIV 15 min + & 17 & 15 \\
HCl & & \\
Proteinase K 0.02\% & 17 & 8 \\
Pepsin 0.01\% & 15 & 3 \\
\hline
\end{tabular}

noma, pretreated in the same way, but with no polymerase in the nucleotide solution.

ASSESSMENT OF SLIDES

Apoptotic cells and morphologically normal nuclei were assessed using a subjective scoring system. Apoptotic cells were recognised by their characteristic microscopic appearances ${ }^{12}$ : shrinkage of single cells associated with chromatin condensation, nucleolar disintegration, and crescentic caps of condensed chromatin at the nuclear periphery, often with loss of the nuclear membrane, and apoptotic bodies composed of condensed fragments of nuclear material and cytoplasm. Zones of necrosis were avoided. Apoptotic cells were scored as follows: 0 , all negative; 1 , weak reaction; 2 moderate reaction; 3 , strong reaction. The morphologically normal nuclei were given 0 for a reaction in less than $1 \%, 1$ for a reaction in $1 \%$ to $50 \%$ of nuclei, 2 for a reaction in over $50 \%$ of nuclei but with an intensity significantly less than the apoptotic bodies, and 3 for a reaction in which the nuclei gave a signal of similar intensity to the apoptotic bodies (in these cases it was often difficult to tell apoptotic cells and normal cells apart). Hence, the "ideal" section would score 3 for apoptotic bodies and 0 for normal nuclei. At least 100 high power fields ( $\times 40$ objective) from each slide were examined; areas were chosen on the basis that they did not show lifting or folding of the tissue section.

The results were analysed statistically with Fisher's exact test. Probabilities quoted are two-sided and are rounded to two decimal places with $\mathrm{p}<0.05$ taken as significant.

\section{Results}

Table 1 shows the scores for the pretreatments. The maximum possible value in each case was 18 (score 3 in all six slides).

When hydrochloric acid was used in addition to trypsin, protease XIV, and protease XXIV, there were increased levels of positivity in both apoptotic and normal nuclei (fig 1). The increase in scores for apoptotic nuclei when hydrochloric acid was used was statistically significant for trypsin $(\mathrm{p}=0.00)$, protease XIV $0.05 \% \quad(p=0.03)$, protease XIV $0.5 \%$ $(p=0.00)$, and protease XXIV for five minutes and 15 minutes incubation ( $p=0.00$ in both cases). The increase in scores for normal nuclei 

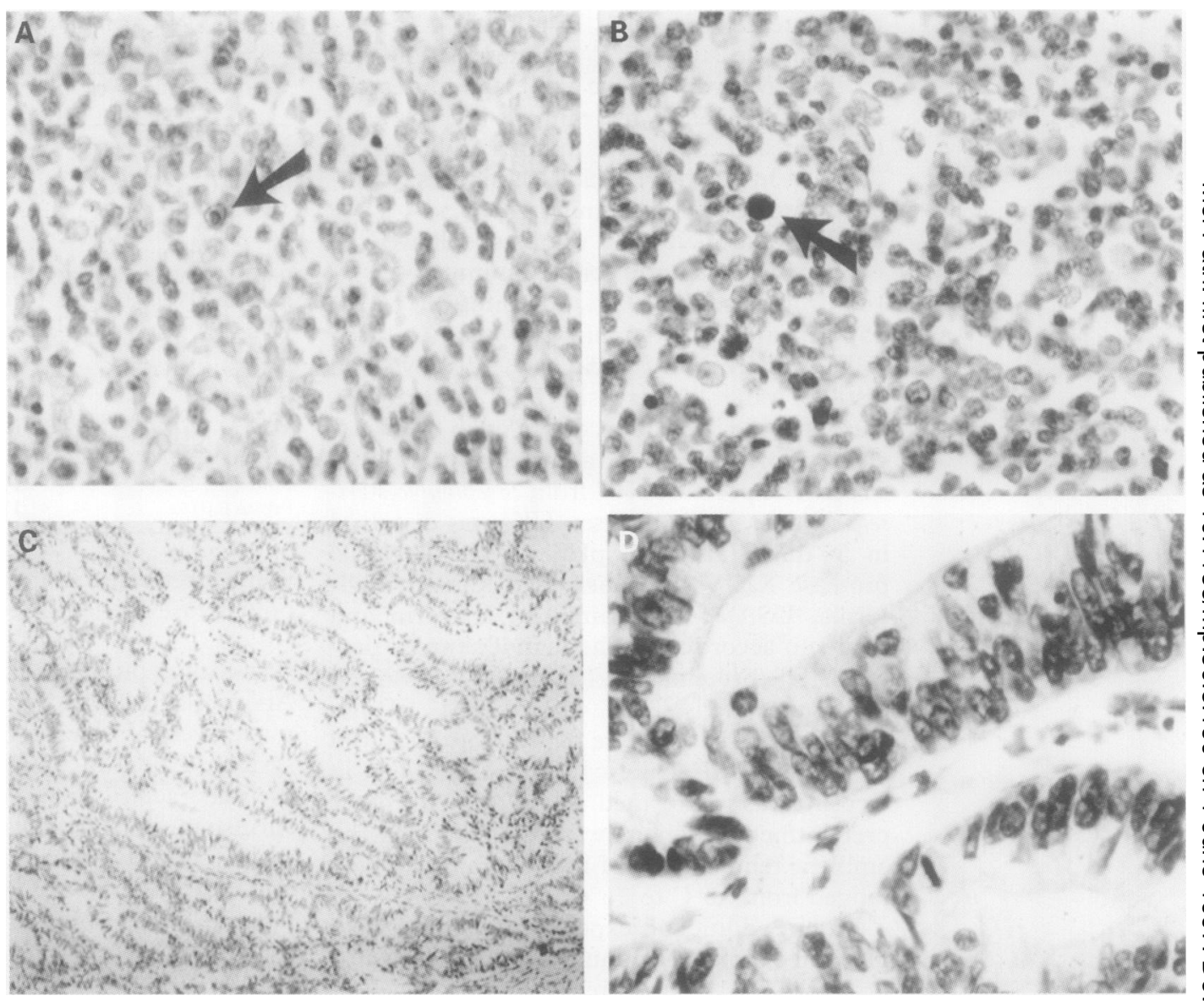

Figure 1 ISEL reactions with different pretreatments. (A) Lymphoma, trypsin $0.1 \%$ alone. There is weak positivity in occasional apoptotic nuclei (arrow), while normal nuclei are negative. (B) Lymphoma, trypsin $0.1 \%$ plus $1 \mathrm{M} \mathrm{HCl}$. The apoptotic nuclei are strongly positive (arrow) and score 3, while the normal nuclei show diffuse positivity but with a lower intensity than the apoptotic nuclei (score 2). (C) Adenocarcinoma, protease XIV 0.5\% alone. Digestion artefact is present but there is no ISEL reaction in any nuclei. (D) Adenocarcinoma, protease XIV $0.5 \%$ plus $1 \mathrm{M} \mathrm{HCl}$. In this field, all nuclei are strongly positive.

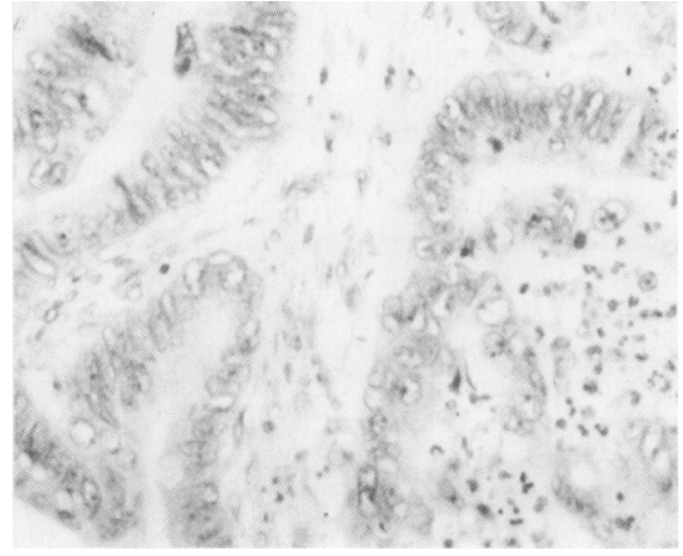

Figure 2 ISEL reaction, adenocarcinoma, pretreated with $1 \mathrm{M} \mathrm{HCl}$ only. In this field there is no reactivity in any nuclei, nor in the necrotic material on the right of the figure.

when hydrochloric acid was used was statistically significant for trypsin $(p=0.01)$, protease XIV $0.5 \%(p=0.00)$, protease XXIV for five minutes $(p=0.03)$, and protease XXIV for 15 minutes $(p=0.00)$.

Some slides showed a mild degree of positivity in apoptotic cells even without any pretreatment, reflected in the total score of 4 (table 1 ). Incubation with either $1 \mathrm{M}$ or $0.1 \mathrm{M}$ hydrochloric acid alone had no effect on the ISEL reaction (fig 2).

Slides pretreated with trypsin or protease XXIV for 60 minutes showed no reaction in

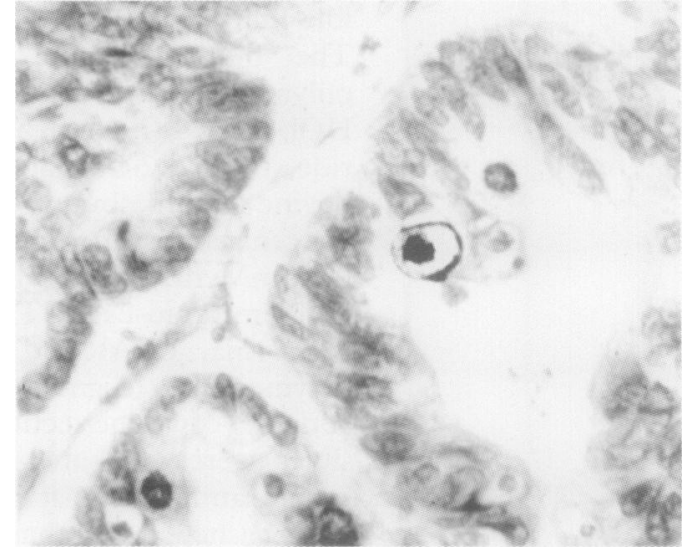

Figure 3 ISEL reaction, adenocarcinoma, pretreated with pepsin in $0.1 \mathrm{M} \mathrm{HCl}$. A strongly positive apoptotic cell is visible near the centre of the figure (score 3), the other nuclei are negative.

any slide in either apoptotic cells or normal nuclei. Morphological digestion effects were visible in these tissues, and in the slides incubated with protease XIV $0.5 \%$ (fig $1 \mathrm{C}$ ).

Both proteinase $\mathrm{K}$ and pepsin gave good results. The signal:noise ratio was best for pepsin; strong reactions in apoptotic cells were seen whereas normal nuclei showed little or no reaction (fig 3 ).

\section{Discussion}

We have demonstrated that the addition of $1 \mathrm{M}$ hydrochloric acid to pretreatment with trypsin, 
protease XIV, and protease XXIV results in significantly stronger ISEL reactions. This finding is similar to observations with in situ PCR, which showed that dilute acid pretreatment may have an important effect on subsequent reactions. ${ }^{14-16}$ The acid may be having an effect on either the DNA associated proteins, the nucleic acid, or both. The solubility of histone proteins may increase at low $\mathrm{pH},{ }^{14}$ while known effects of mineral acids on nucleic acids include depurination (the purine $\mathrm{N}$-glycosyl bond is more labile than the pyrimidine N-glycosyl bond), and phosphodiester bond cleavage with hydrolysis into lower molecular weight fragments. ${ }^{14-16}$ In contrast, DNA is relatively stable under alkaline conditions. ${ }^{16}$

The positive reactions in normal nuclei probably result from DNA nicks incurred during fixation and processing ${ }^{14}$; however, the numbers of such nicks are less than in apoptotic cells. Hence the statement by Ansari et $a l^{2}$ "... . the ISEL technique is selective (rather than specific) for apoptotic nuclei, since these contain a far greater degree of DNA fragmentation."

When morphological digestion effects were visible (protease $\mathrm{XIV}$ at $0.5 \%$, trypsin, and protease XXIV at 60 minutes incubation), there was no ISEL reaction in any nuclei. It appears that even the low level of background positivity observed in slides with no pretreatment can be abolished when overdigestion occurs. These findings confirm the importance of correct pretreatment: false negative ISEL results may be obtained when proteolytic digestion is either excessive or inadequate.

We also found that pretreatment with acid alone had no significant effect. This finding is consistent with pilot studies which showed that slides pretreated with hydrochloric acid alone at $0.1 \mathrm{M}, 0.5 \mathrm{M}$, and $1 \mathrm{M}$ concentrations showed no increase in positive ISEL signals, even with incubation times as long as $30 \mathrm{~min}$ utes (data not shown).

Why did pepsin, proteinase $\mathrm{K}$, and protease XIV result in positive ISEL without a separate acid incubation step, in contrast to trypsin and protease XXIV? In the case of pepsin, which is dissolved in $0.1 \mathrm{M}$ hydrochloric acid, an effect from the low $\mathrm{pH}$ of the solution may obviate the need for subsequent mineral acid treatment. Proteinase $\mathrm{K}$ and protease XIV, however, are not used at acid pH. It is possible that different enzyme activities may be relevant, but this seems unlikely as protease XIV, protease $\mathrm{XXIV}$, and proteinase $\mathrm{K}$ all have a broad spectrum proteolytic activity, in contrast to trypsin, which preferentially cleaves bonds on the carboxyl side of arginine or lysine. ${ }^{17} 18$ One could speculate that steric effects might be involved-for example, the relatively low mo- lecular weight of proteinase $\mathrm{K}(19 \mathrm{kDa})$ might allow it access to parts of the histone complex inaccessible to larger enzymes. ${ }^{19} 20$

The results of this study are consistent with the hypothesis that dilute mineral acid can have an effect on the ISEL reaction that is complementary to, but different from, the effects of proteolytic enzyme treatment. From a practical point of view, workers having problems with consistency in ISEL results may find pepsin a better choice than proteinase $\mathrm{K}$, as it combines proteolysis and acid treatment in one step. Alternatively, one could consider using another proteolytic enzyme combined with hydrochloric acid incubation.

1 Gregory CD. Apoptosis: a role in neoplasia? In: Pusztai L, Lewis CE, Yap E, eds. Cell proliferation in cancer. Oxford Oxford University Press, 1996:342-67.

2 Ansari B, Coates PJ, Greenstein BD, Hall PA. In situ end labelling detects DNA strand breaks in apoptosis and other physiological and pathological states. F Pathol 1993;170:18.

3 Coates PJ, Save V, Ansari B, Hall PA. Demonstration of DNA damage/repair in individual cells using in situ end labelling: association of p53 with sites of DNA damage. $\mathcal{F}$ Pathol 1995;176:19-26.

4 Wijsman JH, Jonker RR, Keijzer R, van de Velde CJH, Cornelisse CJ, van Dierendonck JH. A new method to detect apoptosis in paraffin sections: in situ end-labeling of fragmented DNA. F Histochem Cytochem 1993;41:7-12.

5 Mundle S, Iftikhar A, Shetty V, Alvi S, Dameron S, Gregory $S$, et al. In situ end labelling of DNA to detect apoptotic cell death in a variety of human tumors. Cell Death and Differentiation 1994;1:117-22.

6 Mundle S, Iftikhar A, Shetty V, Dameron S, WrightQuinones V, Marcus B, et al. Novel in situ double labeling for simultaneous detection of proliferation and apoptosis. $\mathcal{F}$ for simultaneous detection of proliferation

7 Gold R, Schmied M, Rothe G, Zischler H, Breitschopf H, Wekerle $\mathrm{H}$, et al. Detection of DNA fragmentation in apoptosis: application of in situ nick translation to cell culture systems and tissue sections. $\mathcal{F}$ Histochem Cytochem 1993;41:1023-30.

8 Du M, Singh N, Husseuin A, Isaacson PG, Pan L. Positive correlation between apoptotic and proliferative indices in gastrointestinal lymphomas of mucosa-associated lymphoid tissue (MALT). $\mathcal{F}$ Pathol 1996;178:379-84

9 Gaffney EF, O'Neill AJ, Staunton MJ. In situ end-labelling, light microscopic assessment and ultrastructure of apoptosis in lung carcinoma. F Clin Pathol 1995;48:1017-21.

10 Gavrieli Y, Sherman Y, Ben-Sasson SA. Identification of programmed cell death in situ via specific labeling of nuclear DNA fragmentation. F Cell Biol 1992;119:493 501.

11 Iwata J, Sonobe H, Furihata M, Ido E, Ohtsuki Y. High frequency of apoptosis in infantile capillary haemangioma. $\mathcal{F}$ Pathol 1996;1 179:403-8.

12 Hiraishi K, Suzuki K, Hakomori S, Adachi M. Ley antigen expression is correlated with apoptosis (programmed cell death). Glycobiology 1993;3:381-90.

13 Gold R, Schmied M, Giegerich G, Breitschopf H, Hartung $\mathrm{HP}$, Toyka KV, et al. Differentiation between cellular apoptosis and necrosis by the combined use of in situ tailing and nick translation techniques. Lab Invest 1994;71:219-25.

14 Lewis FA. In situ PCR-myth or magic? f Cell Pathol 1996; 1:13-23.

15 Teo IA, Shaunak S. Polymerase chain reaction in situ: an appraisal of an emerging technique. Histochem $\mathcal{f} 1995 ; 27$ 647-59.

16 Kochetov NK, Budovskii EI. Organic chemistry of nucleic acids. London: Plenum Press, 1971

17 Keil B. Specificity of proteolysis. Berlin: Springer-Verlag 1992

18 Beynon RJ, Bond JS. Proteolytic enzymes: a practical approach Oxford: IRL Press, 1989.

19 Dattagupta JK, Fujiwara T, Grishin EV, Lindner K, Manor PC, Pieniazek NJ, et al. Crystallization of the fungal enzyme proteinase $\mathrm{K}$ and amino acid composition. $\mathcal{F}$ Molec Bio 1975;97:267-71.

20 Barman TE. Enzyme handbook. Berlin: Springer-Verlag, 1969. 